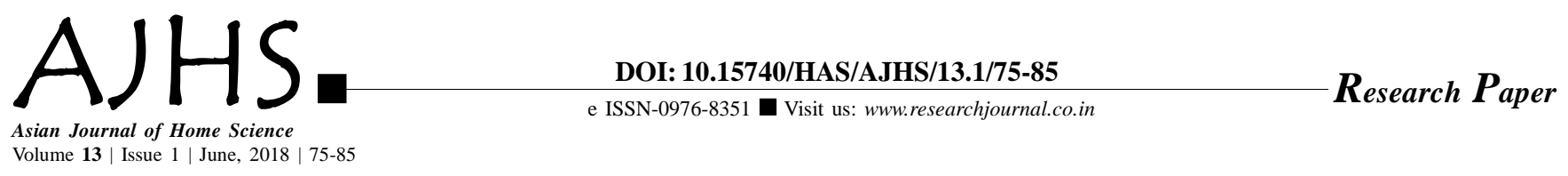

\title{
Impact of computer tailored nutrition application software on knowledge stage of diabetics
}

Renu Paliwal and Aarti Sankhala

Received: 29.01.2018; Revised: 20.03.2018; Accepted: 07.04.2018

See end of the paper for authors' affiliations

Renu Paliwal

Department of Foods and

Nutrition, College of Home

Science, Maharana Pratap

University of Agriculture and

Technology, Udaipur (Rajasthan)

India

Email : renu8543@gmail.com
ABSTRACT : Diabetes is now-a-days occupying the central position around the globe. It is therefore essential to condense its likelihood and the best way to do so is education, only education can reduce the occurrence as well as can help in better management of the disease. With the help of present software user can understand different aspects of the diseases from theoretical as well as practical point of view. In practical side user can create his/ her profile and accordingly obtain results on BMI and health risk according to the waist hip ratio classification, similarly he can judge his/ her knowledge or risk in the disease so that he/ she can take preventive measures in future. Biochemical presentation shows disease status whether improving or declining with the help of diary maintenance. Tracking diet and activity is equally important so as to understand the concept of energy balance. The developed software was evaluated on different criteria by a panel of 18 experts on five point scale ranging from very good to very poor for most of the parameters. and in majority of section it secured the MWS above 4.61 i.e. which justifies the significance of the developed system.

KEY WORDS: Computer, Tailored nutrition, Software, Diabetes

- HOW TO CITE THIS PAPER : Paliwal, Renu and Sankhala, Aarti (2018). Impact of computer tailored nutrition application software on knowledge stage of diabetics. Asian J. Home Sci., 13 (1) : 75-85, DOI: 10.15740/HAS/AJHS/13.1/75-85. Copyright@ 2018: Hind Agri-Horticultural Society. 